\title{
Outcome of restorative proctocolectomy with ileal reservoir for ulcerative colitis: comparison of distal colitis with more proximal disease
}

\author{
D N Samarasekera, J F Stebbing, M G W Kettlewell, D P Jewell, N J McC Mortensen
}

\begin{abstract}
Background-An increasing number of patients with severe or refractory ulcerative colitis involving only the rectum and sigmoid colon are being offered restorative proctocolectomy with ileal reservoir but very few data are available concerning the outcome for these patients.

Aim-This study was designed to compare the outcome of ileal pouch procedures for distal ulcerative colitis with procedures performed for more extensive disease.

Patients-A consecutive series of 177 patients undergoing restorative proctocolectomy for ulcerative colitis between January 1984 and December 1994.

Methods-Data were collected prospectively in a dedicated ileal pouch database and included demographic details, indication for surgery, surgical procedures performed, early $(<30$ days) and late morbidity, functional outcome, and histopathology.

Results-There was no mortality in the series. The incidence and range of early morbidity ( $<30$ days) and the functional outcome (daytime stool frequency, nocturnal frequency, and the incidence of incontinence) were similar for all groups. Log rank analysis of Kaplan-Meier estimates showed no significant difference
\end{abstract}

TABLE I Definition of patient groups by pathological (macroscopic and microscopic) assessment of colon

\begin{tabular}{|c|c|c|}
\hline Group & Number & Definition \\
\hline Distal colitis & 20 & Disease limited to rectum and sigmoid colon \\
\hline Left sided colitis & 22 & $\begin{array}{l}\text { Proximal limit of disease between sigmoid colon and splenic } \\
\text { flexure }\end{array}$ \\
\hline $\begin{array}{l}\text { Substantial and } \\
\text { extensive colitis }\end{array}$ & 29 & $\begin{array}{l}\text { Proximal limit of disease between splenic flexure and ascending } \\
\text { colon }\end{array}$ \\
\hline Total colitis & 106 & $\begin{array}{l}\text { Whole colon involved with at least microscopic involvement of } \\
\text { caecum }\end{array}$ \\
\hline
\end{tabular}

TABLE II Summary of ileal reservoir procedures performed

\begin{tabular}{llclc}
\hline & $\begin{array}{l}\text { Distal } \\
\text { colitis } \\
(n=20)\end{array}$ & $\begin{array}{l}\text { Left sided } \\
\text { colitis } \\
(n=22)\end{array}$ & $\begin{array}{l}\text { Substantial and } \\
\text { extensive colitis } \\
(n=29)\end{array}$ & $\begin{array}{l}\text { Total } \\
\text { colitis } \\
(n=106)\end{array}$ \\
\hline Pouch design & 14 & 17 & 20 & 71 \\
J & 5 & 4 & 6 & 29 \\
S & 1 & 1 & 3 & 6 \\
Anastomosis & 10 & 18 & 21 & 82 \\
$\quad$ Stapled & 10 & 4 & 8 & 24 \\
$\quad$ Handsewn & 18 & 22 & 28 & 95 \\
Mucosectomy & 2 & 0 & 1 & 11 \\
$\quad$ No & 11 & 15 & 21 & 79 \\
Yes & 9 & 7 & 8 & 27 \\
$\quad$ Yefunctioning ileostomy & $17(11-33)$ & $14(9-38)$ & $20(10-47)$ & $15(4-103)$ \\
$\quad$ No & & & & \\
$\quad$ Closure (median (range) weeks) & & & & \\
\hline
\end{tabular}

between groups in the likelihood of developing pouchitis $(\mathbf{p}>0 \cdot 2)$.

Conclusions-Patients undergoing restorative proctocolectomy for distal colitis experience a similar outcome to patients with more extensive disease. These data refute the hypothesis that pouchitis is more common in patients with total colitis. (Gut 1996; 38: 574-577)

Keywords: ulcerative colitis, restorative proctocolectomy, ileal reservoir.

Restorative proctocolectomy with ileal reservoir (RPC) has revolutionised surgery for ulcerative colitis. The procedure is curative, involving resection of all the diseased colon and rectum, restores intestinal continuity and, in the presence of a normally functioning anal sphincter, preserves continence. ${ }^{1-3}$ RPC is clearly indicated in patients who have undergone emergency colectomy for complicated acute severe colitis, in patients with extensive disease poorly controlled by medical treatment, and in those with high grade dysplasia or occult carcinoma on colonoscopic surveillance. However, an increasing number of patients with disease involving only the rectum and distal colon are being offered RPC when medical treatment fails to control chronic debilitating symptoms, such as recurrent bleeding, urgency, and intolerable frequency of defecation, or when treatment is itself poorly tolerated.

All patients undergoing RPC require counselling about the potential morbidity and variety of functional outcomes from the procedure but very few data are available concerning the outcome for patients with limited disease extent. This study therefore sought to examine the outcome of RPC for patients with distal colitis and to compare this with the outcome for patients with more extensive disease.

\section{Methods}

A total of 177 patients have undergone RPC for ulcerative colitis between January 1984 and December 1994. All pouch procedures were performed by three consultant surgeons (the late Emanoel Lee, MK, and NM).

Data were collected prospectively in a dedicated ileal pouch database and included demographic details, indication for surgery, surgical procedures performed, early ( $<30$ days) and late morbidity, functional outcome, and histopathology. Patients were divided into four 
TABLE III Demographic details and indications for surgical intervention

\begin{tabular}{lcccc}
\hline & $\begin{array}{l}\text { Distal } \\
\text { colitis } \\
(n=20)\end{array}$ & $\begin{array}{l}\text { Left sided } \\
\text { colitis } \\
(n=22)\end{array}$ & $\begin{array}{l}\text { Substantial and } \\
\text { extensive colitis } \\
(n=29)\end{array}$ & $\begin{array}{l}\text { Total } \\
\text { colitis } \\
(n=106)\end{array}$ \\
\hline $\begin{array}{l}\text { Median age at time of RPC } \\
\text { Male:female }\end{array}$ & $37(24-52)$ & $35(21-55)$ & $40(14-58)$ & $31(6-67)$ \\
$\begin{array}{l}\text { Indication for RPC }(\%) \\
\text { Acute severe disease }\end{array}$ & $11: 9$ & $8: 11$ & $14: 8$ & $66: 40$ \\
$\begin{array}{l}\text { Chronic symptomatic disease } \\
\text { High grade dysplasia }\end{array}$ & $10(35)$ & $8(36)$ & $9(31)$ & $55(52)$ \\
Carcinoma & $2(10)$ & $13(59)$ & $19(66)$ & $48(45)$ \\
& $1(5)$ & 0 & 0 & $2(3)$ \\
\hline
\end{tabular}

${ }^{\star} \mathrm{RPC}$ usually performed as an elective procedure after emergency colectomy.

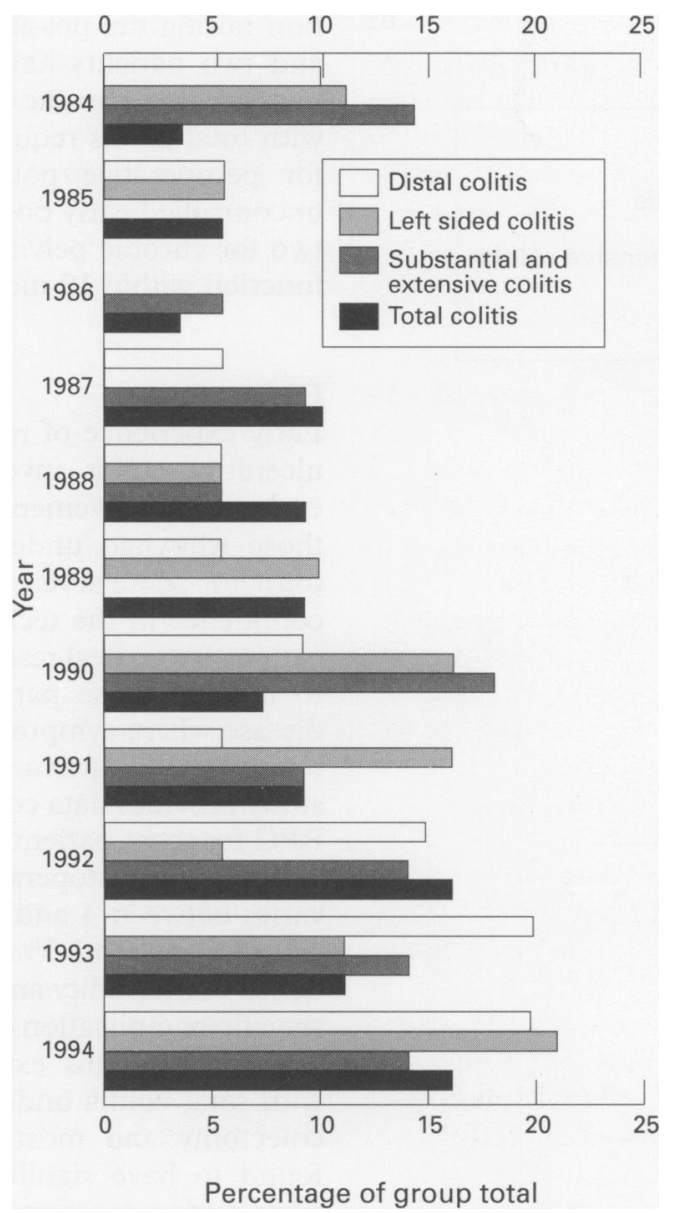

Figure 1: Distribution of pouch procedures are broadly similar for each group throughout the series. In any given year, the procedures performed for each group are shown independently as a percentage of the overall group total.

groups according to disease extent, which was determined by pathological examination of the resected colon (Table I).

TABLE IV Early (<30 days) morbidity after ileal reservoir procedure

\begin{tabular}{lllll}
\hline & $\begin{array}{l}\text { Distal } \\
\text { colitis } \\
(n=20)\end{array}$ & $\begin{array}{l}\text { Left sided } \\
\text { colitis } \\
(n=22)\end{array}$ & $\begin{array}{l}\text { Substantial and } \\
\text { extensive colitis } \\
(n=29)\end{array}$ & $\begin{array}{l}\text { Total } \\
\text { colitis } \\
(n=106)\end{array}$ \\
\hline Overall morbidity (\%) & $7(35)$ & $6(27)$ & $10(34)$ & $39(37)$ \\
Procedure-specific complications (\%) & $4(20)$ & $4(18)$ & $8(27)$ & $25(24)$ \\
Pelvic or intra-abdominal sepsis & 1 & 1 & 3 & 6 \\
Peritonitis (anastomotic dehiscence) & 0 & 0 & 1 & 0 \\
Pouch haemorrhage & 0 & 0 & 1 & 5 \\
Pouch ischaemia & 1 & 0 & 1 & 2 \\
Small bowel obstruction & 1 & 1 & 0 & 4 \\
Small bowel perforation & 0 & 0 & 0 & 1 \\
'High output' ileostomy/pouch & 1 & 0 & 0 & 4 \\
Wound infection & 0 & 1 & 0 & 4 \\
Ileostomy complication & 0 & 1 & 1 & 2 \\
General (for example, UTI, chest infection) (\%) & $3(15)$ & $2(9)$ & $2(7)$ & $17(16)$ \\
\hline
\end{tabular}

UTI = urinary tract infection.
Operative technique

Table II outlines the pouch designs, anastomotic technique, and the use of mucosectomy and defunctioning ileostomy in each patient group. In most patients, nerve sparing rectal dissection and a stapled J pouch anal anastomosis were performed. In all patients undergoing mucosectomy, an endoanal circumferential incision was made to define the distal limit of dissection and the anastomosis was handsewn with absorbable sutures.

\section{Follow up}

Patients with functioning pouches had their first outpatient follow up 4-12 weeks after ileostomy closure with further review at 3,6 , 12 , and 18 months. Thereafter, they were reviewed annually. Longterm pouch function was assessed by collecting data on stool frequency and continence. Incontinence was defined as major (gross leakage, wearing pads all the time) or minor (occasional faecal seepage, spotting of underclothes). Diagnosis of pouchitis required appropriate clinical, endoscopic, and histological features. ${ }^{4}$

Statistical analysis was performed using the $\chi^{2}$ test for frequency variables and $\log$ rank analysis of Kaplan-Meier estimates for the incidence of pouchitis. A value of $p<0.05$ was considered significant.

\section{Results}

Table III shows the demographic details and indications for surgical intervention in each group. The distribution of the procedures for each group throughout the series was similar (Fig 1).

\section{Early morbidity}

There was no mortality in this series. Table IV outlines early ( $<30$ days) morbidity rates for each group and details procedure specific complications. Overall morbidity was similar for all groups and the frequency and range of procedure specific complications was as expected after pouch surgery. The median postoperative stay was similar for all groups (11-13 days).

\section{Functional outcome}

Figure 2 summarises data concerning functional outcome. The median length of follow up for patients with a functioning pouch was broadly similar for all groups permitting valid comparison of functional outcome and longterm morbidity. There were no significant differences in daytime stool frequency, nocturnal frequency, and the incidence of incontinence between groups.

\section{Pouchitis}

Two patients with distal colitis, four with left sided colitis, four with substantial and extensive colitis, and 21 with total colitis developed pouchitis during follow up. Log rank analysis of Kaplan-Meier estimates showed no significant 


$\begin{array}{lllll} & \text { Distal } & \text { Left sided } & \begin{array}{l}\text { Substantial/ } \\ \text { extensive }\end{array} & \text { Total } \\ \text { No of patients } & 20 & 21 & 27 & 100 \\ \text { Median (range) follow up (months) } & 20(3-112) & 36(2-122) & 32(1-100) & 23(1-121) \\ \text { Perfect continence (\%) } & 16(80) & 15(71) & 23(78) & 82(82) \\ \text { Minor incontinence (\%) } & 4(20) & 6(29) & 6(22) & 16(16) \\ \text { Major incontinence (\%) } & 0 & 0 & 0 & 2(2)\end{array}$
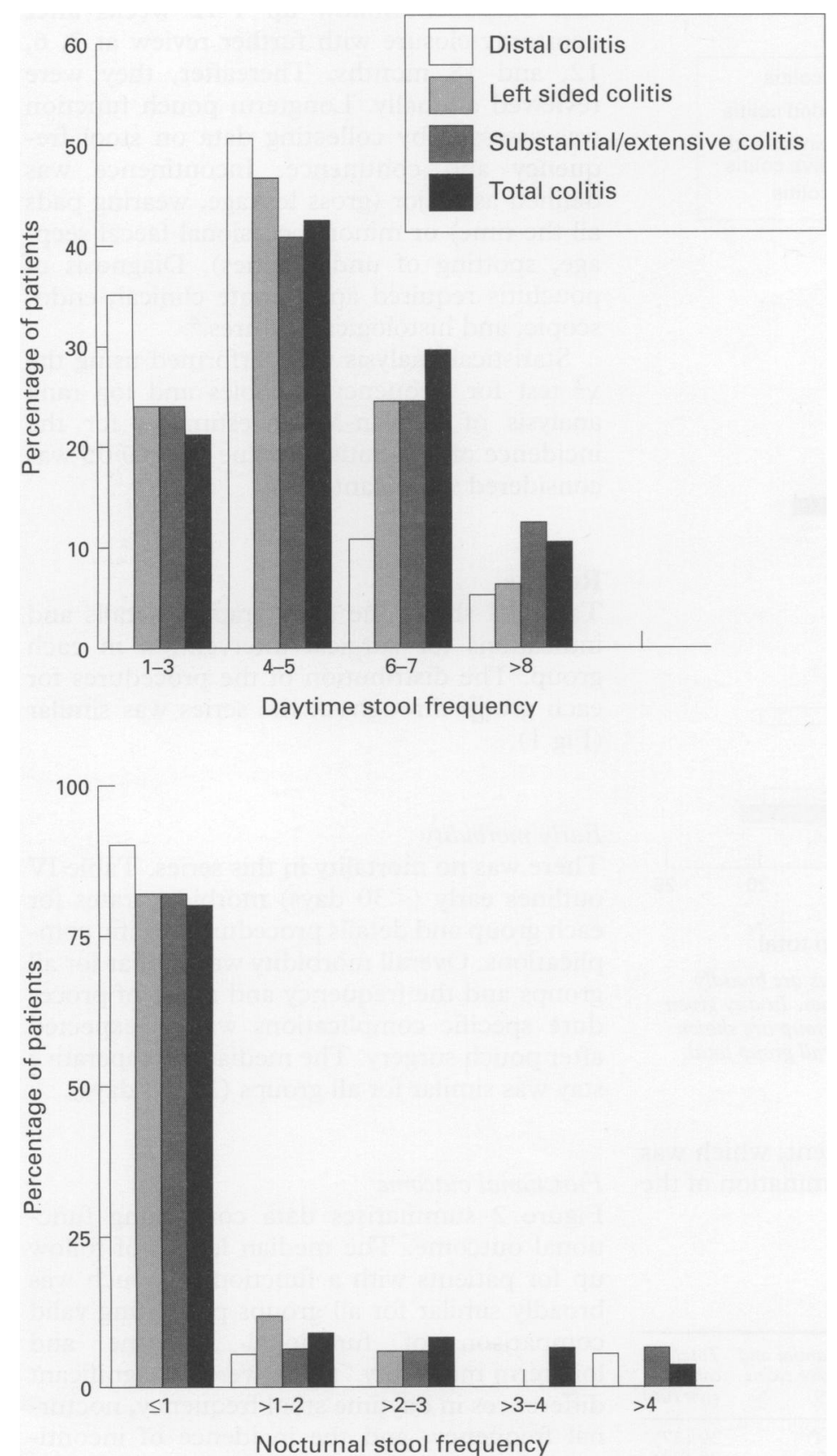

Figure 2: Data concerning stool frequency and continence for patients with a functioning pouch after restorative proctocolectomy.

difference between groups in the likelihood of developing this complication (Fig 3, p >0.2).

Late morbidity and pouch failures

Four patients (one distal, one left sided, and two total colitis) developed pouch-vaginal fistula as a delayed complication of pelvic sepsis and required temporary defunctioning with an ileostomy.

There were no pouch failures in the group with distal colitis, although one patient required on table revision of their pouch for ischaemia. One patient with left sided disease required pouch excision for pelvic sepsis. In the group with substantial and extensive colitis, one pouch was removed at operation for ischaemia, one patient has been defunctioned because of persistent pouch inflammation raising the possibility of Crohn's disease, and two patients have had successful pouch revision after chronic pelvic sepsis. Six patients with total colitis required pouch excision, two for peroperative pouch ischaemia, two for uncontrolled early postoperative bleeding, and two for chronic pelvic sepsis with poor pouch function within 12 months of surgery.

\section{Discussion}

Early experience of restorative procedures for ulcerative colitis involved patients who had extensive involvement of the large bowel or those who had undergone emergency colectomy for acute severe disease. With increasing confidence in the technique, the relative indications for an ileal reservoir have been widened to include those patients with more limited disease where symptoms are poorly controlled by optimal longterm medical treatment. This study provides data concerning the outcome of RPC for these patients.

The early postoperative morbidity after RPC varies between 4 and $60 \% 0^{3-10}$ and mortality ranges from 0 to $1.5 \% .^{36} 11-15$ The overall incidence of morbidity and the range of procedure specific complications seen in our series are in keeping with this experience. More patients with total colitis underwent initial emergency colectomy and most of these patients were found to have significant small bowel adhesions during proctectomy and pouch construction. The need for adhesiolysis and more difficult dissection probably increases the likelihood of serious morbidity and in the total colitis group, early reoperation was required for three patients with small bowel obstruction, one patient with intrabdominal sepsis, and four patients with pouch haemorrhage. By contrast, most patients with distal colitis had an adhesion free peritoneal cavity and no patient required re-operation. For all groups in our series the rates of pelvic sepsis compare favourably with published experience where rates vary between 0 and $24 \% .{ }^{5-9} 1617$

The functional outcome for patients undergoing RPC for distal colitis is comparable to that for patients with more extensive disease. Daytime stool frequency for all groups was acceptable and the vast majority of patients enjoyed good nocturnal control. Relief from urgency, a significant pre-operative symptom in patients with uncontrolled distal colitis, is an additional benefit which, in combination with maintenance of the quality of continence, adds significantly to quality of life. Most patients 


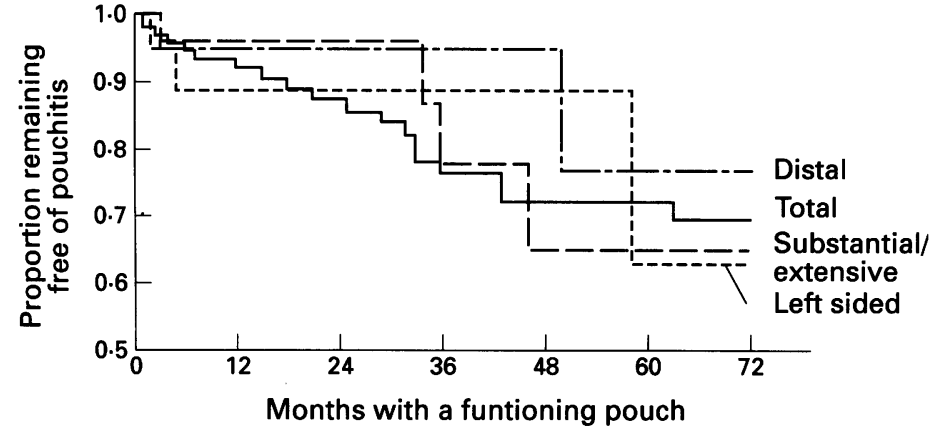

Number at risk

$\begin{array}{rcccccc}\text { Distal colitis } & 20 & 14 & 11 & 10 & 7 & 6 \\ \text { Left sided colitis } & 21 & 15 & 11 & 8 & 7 & 5 \\ \begin{array}{r}\text { Substantial/ } \\ \text { extensive colitis }\end{array} & 27 & 19 & 12 & 8 & 5 & 5 \\ \text { Total colitis } & 102 & 68 & 53 & 41 & 32 & 28\end{array}$

Figure 3: Plot of Kaplan-Meier estimates of the proportion of patients remaining free of pouchitis during follow up. Data censored at 60 months. Log rank analysis showed no significant difference between the groups $(p>0 \cdot 2)$.

experience continued improvement in pouch function over the first six to 12 months resulting from adaptation of the pouch and recovery in full sphincter function. ${ }^{1-15} 1819$ A low incidence of sexual dysfunction probably reflects avoidance of radical dissection techniques and it is of note that in three of four patients who suffered erectile dysfunction pelvic dissection was performed in the mesorectal plane, which may carry a higher risk of damage to the pelvic nerves than perimuscular rectal dissection.

The reported incidence of pouchitis affecting ileal reservoirs varies between 7 and $45 \%^{20-22}$ but if strict clinical, endoscopic, and histological criteria are applied to the diagnosis, as in this series, the true incidence seems to fall between 10 and $20 \% .^{22-24}$ In our study the Kaplan-Meier technique was used to estimate the proportion of patients in each group remaining free of pouchitis as a function of time. This technique is suited to comparatively small samples and takes account of patients still under open follow up (censoring). Log rank analysis, appropriate for groups enjoying similar lengths of follow up, was used to test for differences in the experience of each group. Our data failed to show a significant difference in the incidence of pouchitis between the groups and does not support the assertion in previous studies that pouchitis is more common in patients with total colitis. ${ }^{25-27}$

Pouch failure (excision or defunctioning of the pouch) occurs as a result of early technical problems (ischaemia or haemorrhage), pelvic sepsis or delayed diagnosis of Crohn's disease. Cumulative experience suggests that around $6 \%$ of pouches fail ${ }^{28}$ ( 0 and $6 \%$ in our series) and this should be remembered when counselling patients before surgery as pouch removal may be devastating for the patient.

The results of this study suggest that patients undergoing RPC for distal colitis experience a similar outcome, in terms of morbidity and functional outcome, to patients with more extensive disease. The possibility of a pouch procedure should therefore be discussed with patients suffering longterm debilitating symptoms from distal colitis and with those requiring surgery for acute severe disease, high grade dysplasia or carcinoma.

Presented in part to the British Society of Gastroenterology in Manchester, April 1995 and published in abstract form as Gut 1995; 36 (suppl 1): A24.

1 Keighley MRB. Pouchitis. Br f Surg 1994; 81: 1091-2.

2 Parks AG, Nicholls RJ. Proctocolectomy without ileostomy for ulcerative colitis. BMF 1978; 2: 85-8.

3 Pena JP, Gemlo BJ, Rothenberger DA. Ileal pouch anal anastomosis: state of the art. Baillieres Clin Gastroenterol 1992; 6: 113-28.

4 Shepherd NA, Hulten L, Tytgat GN, Nicholls RJ, Nasmyth DG, Hill MJ, et al. Pouchitis. Int f Colorectal Dis 1989; 4: 205-29.

5 Williams NS, Johnston D. The current state of mucosal proctectomy and ileoanal anastomosis in the surgical treatment of ulcerative colitis and adenomatous polyposis. Br F Surg 1985; 72: 159-68.

6 Nasmyth DG, Williams NS, Johnston D. Comparison of the function of triplicated and duplicated pelvic ileal reservoirs after mucosal proctectomy and ileoanal anastomosis voirs after mucosal proctectomy and ileoanal anastomosis 1986; 73: 361-6.

7 Harms BA, Hamilton JW, Yamamoto DT, Starling JR. Quadruple loop (W) ileal pouch reconstruction after proctocolectomy; analysis and functional results. Surgery 1987; 102: 561-7.

8 Morgan RA, Manning PB, Coran AG. Experience with the straight endorectal pull through for the management of ulcerative colitis and familial adenomatous polyposis in children and adults. Ann Surg 1987; 206: 595-9.

9 Galandiuk S, Scott NA, Dozois RR, Kelly KA, Ilstrup DM, Beart RW, et al. Ileal-pouch anal anastomosis. Ann Surg 1990; 212: 446-53.

10 Wexner SD, Wong WD, Rothenberger DA, Goldberg SM The ileoanal reservoir. Am $\mathcal{F}$ Surg 1990; 159: 178-83.

11 Pemberton JH, Beart RW Jr, Dozois RR, Wolff BG, Ilstrup DM. Ileal pouch anal anastomosis for chronic ulcerative colitis: long term results. Ann Surg 1987; 206: 504-13.

12 Becker JM, Raymond JL. Ileal pouch anal anastomosis: a single surgeon's experience with 100 consecutive cases. Ann Surg 1986; 204: 375-81.

13 Cohen Z, McLeod RS, Stern H, Grant D, Nordgren S. The pelvic pouch and ileo-anal anastomosis procedure: surgical technique and initial results. Am $\mathcal{F}$ Surg 1985; 150: 601-7.

14 Nicholls RJ, Pezim ME. Restorative proctocolectomy with ileal reservoir for ulcerative colitis and familial adenomatous polyposis: a comparison of three reservoir designs. tous polyposis: a comparis.

15 Schoetz DJ Jr, Coller JA, Veidenheimer MC. Ileo-anal reservoir for ulcerative colitis and familial polyposis. Arch Surg 1986; 121: 404-9.

16 Scott NA, Dozois RR, Beart RW, Pemberton JH, Wolff BG, Ilstrup DM. Postoperative intra-abdominal and pelvic sepsis complicating ileal pouch anal anastomosis. Int $\mathscr{f}$ Colorectal Dis 1988; 3: 149-52.

17 Pemberton JH, Kelly KA, Beart RW, Dozois RR, Wolff BG, Ilstrup DM. Ileal pouch anal anastomosis for chronic ulcerative colitis: long term results. Ann Surg 1987; 206: 504-13.

18 Sagar PM, Holdsworth PJ, Johnston D. Correlation between laboratory findings and clinical outcome after restorative proctocolectomy: serial studies in 20 patients after end to end pouch anal anastomosis. Br F Surg 1991; after end to $67-70$.

19 Grotz RL, Pemberton JH. The ileal pouch operation for ulcerative colitis. Surg Clin N Am 1993; 73: 908-32.

20 Dozois RR, Goldberg SM, Rothenberger DA, Utsunomiya J, Nicholls RJ, Cohen Z, et al. Symposium: restorative proctocolectomy with ileal reservoir. Int $\mathcal{f}$ Colorectal Dis 1986; 1: 2-19.

21 McIntyre PB, Pemberton JH, Wolff BG, Beart RW, Dozois RR. Comparing functional results one year and ten years after ileal pouch-anal anastomosis for chronic ulcerative colitis. Dis Colon Rectum 1994; 37: 303-7.

22 De Silva HJ, Kettlewell MGW, Mortensen NJ, Jewell DP. Acute inflammation in ileal pouches (pouchitis). European

23 Moskowitz RL, Shepherd NA, Nicholls RJ. An assessment Moskowitz RL, Shepherd NA, Nicholls RJ. An assessment
of inflammation in the reservoir after restorative proctocolectomy with ileoanal reservoir. Int $\mathcal{f}$ Colorectal Dis 1986; 1: 167-74.

24 Kock NG. Continent ileostomy. In: Lee ECG, ed. Surgery of inflammatory bowel disorders. Edinburgh: Churchill Livingstone, 1987: 65-80.

25 Luukkonen $\mathbf{P}$, Järvinen $H$, Tanskanen $M$, Kahri $A$ Pouchitis-recurrence of the inflammatory bowel disease? Gut 1994; 35: 243-6.

26 Shepherd NA. The pelvic ileal reservoir: pathology and pouchitis. Neth 7 Med 1990; 37: S57-64.

27 Farrands PA, Shepherd NA, Nicholls RJ. Ileal reservoir inflammation (pouchitis) after restorative proctocolectomy. Gut 1988; 29: A1486.

28 Becker JM. Ileal pouch-anal anastomosis: current status and controversies. Surgery 1993; 113: 599-602. 